\title{
Effects of augmented reality technology in a mobile touring system on university students' learning performance and interest
}

\author{
Kai-Yi Chin \\ School of Big Data Management, Soochow University, Taiwan \\ Ching-Sheng Wang \\ Department of Computer Science and Information Engineering, Aletheia University, Taiwan
}

\begin{abstract}
In this study, we proposed an augmented reality- (AR-) based mobile touring system for an authentic learning activity, which enables students to observe and learn key information regarding cultural heritage sites. To evaluate the effectiveness of the proposed system, we conducted an experiment in a cultural heritage course at a Taiwanese university. A total of 72 students were divided into two groups and randomly assigned to an experimental group who learned with the AR-based mobile touring system and a control group who learned with a conventional mobile touring system. The experimental results show that the AR-based mobile touring system significantly improved the students' memorising dimension of learning achievement, as compared with a conventional mobile touring system. Moreover, the positive impact of the proposed system on students' actualised interest and task-based interest factors provide a particularly encouraging result for outdoor experiences. These experimental results also suggest the potential of AR technology to increase students' learning interest and improve their learning achievements in outdoor settings. Therefore, we suggest that, when applying an AR-based mobile touring system in authentic learning activities, AR virtual objects should be designed appropriately, in order that the content recall performance and learning interest are enhanced.
\end{abstract}

Implications for practice or policy:

- Teachers may need to consider using an AR-based mobile touring system for outdoor learning activities.

- First-year student learning achievements and interest can be improved by an AR-based mobile touring system.

- First-year student learning performance and interest can be improved by AR technology.

- The usefulness of AR technology can be proved through a comparison of experimental designs.

Keywords: augmented reality, mobile devices, mobile learning, authentic learning activity, cultural heritage courses

\section{Introduction}

Recently, the rapid advancement of handheld devices and sensing technologies has provided opportunities for students to learn without the limitations of time and location (Chiang et al., 2014a, 2014b; Liu et al., 2012) and is regarded as a potential approach to facilitate students' learning in real-world environments (Hwang et al., 2016). Several studies have reported the importance of applying mobile technology to assist students' learning in rich physical environments, such as museums, natural parks and on campus. For example, Chu et al. (2010) developed a mobile learning system that guided students to observe butterflies and learn the characteristics of plants on a school campus. Ogata and Yano (2004) proposed the use of JAPELAS and TANGO systems on mobile devices to guide students through learning common Japanese expressions that are polite and appropriate in social situations.

Most mobile learning studies have emphasised that the adoption of digital learning method supports realworld learning scenarios (Y. S. Chang, 2019; Chiang et al., 2014a, 2014b; Liu et al., 2012). Furthermore, the importance of interactions between digital learning technology and the physical environment need to be stressed to attract students' attention and effectively promote their personal knowledge (S. C. Chang \& 
Hwang, 2018; Moorthy et al., 2019). Among various emerging technologies, augmented reality (AR) has been recognised as a promising technology that can help students in dealing with physical tasks with support from mobile devices (Aguayo et al., 2017; Chittaro \& Ranon, 2007). For example, students can view a virtual learning object from the actual environment through the use of a mobile phone, which enables them to obtain instant feedback and guidance in real-world learning scenarios and further increases their learning perceptions and motivations (Bursztyn et al., 2017; Chu et al., 2016; Yilmaz, 2016). Through the use of AR technology, students' expression of spatial cognition, experiment operation ability and collaborative learning can be enhanced in real-world learning activities (S. C. Chang \& Hwang, 2018; Choi \& Baek, 2011).

Some researchers have reported that AR has potential educational uses in many different domains, such as science, language, engineering and history (Aguayo et al., 2017; Cheng \& Tsai, 2013; Ibáñez \& Kloos, 2018; Wu et al., 2013). These studies have pointed out that AR is able to enhance spatial ability, practical skills, conceptual understanding and scientific inquiry learning in real-world environments (Bujak et al., 2013; Ibáñez \& Kloos, 2018). For example, S. C. Chang and Hwang (2018) proposed an AR-based flipped learning system to improve students' learning performance and critical thinking tendency in an elementary school natural science course. Nagata et al. (2017) used an AR and Mobile Pedestrian Navigation app to develop a mobile application for teaching the cultural heritage of Chile; they also proved that this mobile application can significantly improve students' educational performance. Wei et al. (2015) also adopted AR technology in creative design courses and further improved students' learning motivation and their abilities in creative design.

Although AR has proven to be effective in supporting real-world learning activities, it is questionable to depend completely on technologies to promote students' learning performance (Hwang et al., 2016). The educational values of AR not only depend on the use of technologies but are also closely related to how $\mathrm{AR}$ is designed, implemented and integrated into formal and informal learning settings (Wu et al., 2013). Chu (2014) further reported a number of negative effects associated with using AR on field trips, which negatively impacted students' learning achievement when they used mobile devices to engage in authentic learning activities. Without carefully integrating the digital learning content into the real-world environment, this situation may result in a frustrated learning performance and reduced efficiency for students (Chu, 2014; Hwang et al., 2016; Liu et al., 2012). In other words, authentic learning activities typically focus on real-world complex problems and use role-playing exercises and problem-based solutions, as well as participation in virtual communities of practice. Such learning environments inherently contain multiple disciplines and various perspectives, and thereby, easily lead to cognitive overload in learning (C. C. Chen \& Huang, 2012; Chin et al., 2019; Hwang \& Chang, 2011; Liu et al., 2012). It is easy to understand the difficulties in applying AR technology in authentic learning activities.

In this study, an AR-based mobile touring system was proposed to increase students' learning interest as well as their learning achievements in outdoor settings. We also conducted an experiment in a cultural heritage course at a Taiwanese university to evaluate the learning effectiveness of the proposed system. Cultural heritage courses are usually used to provide students with the opportunity to absorb architectural knowledge regarding historical buildings and to become aware of the cultural context of the design, and further focus on protection works of tangible cultural heritage. Such courses are taught in a way that enables students to visit several renowned historical buildings in person, through field trips or outdoor experiences. Therefore, the proposed system acts as an assisting tool which supports students to observe and learn key information regarding cultural heritage sites and access a more authentic learning experience overall. The goal of this study was to explore whether the combination of AR virtual objects into the AR-based mobile touring system for cultural heritage courses is better able to encourage university students' learning performance and interest, as compared with a conventional mobile touring system, which introduces learning content through the use of multimedia materials without AR technology.

\section{Literature review}

\section{Mobile learning for authentic learning activities}

Over the past decade, many educational researchers have highlighted the necessity of incorporating authentic learning activities into courses (C. C. Chen \& Huang, 2012; Hwang \& Chang, 2011; Liu et al., 2012) and asserted that working with problems from real-world environments is beneficial for students' 
higher learning. The published studies have ascertained that authentic learning activities can intensify student learning experiences within physical environments and combine learning content with unique processes to achieve improved student understanding (Hwang \& Wu, 2014; Tsai \& Hwang, 2013). Thus, such learning methods can motivate students to persevere at finishing learning tasks despite their initial disorientation or frustration.

Currently, most teachers adopt conventional outdoor learning methods to create authentic learning activities for their students, as they usually face the challenge of effectively using computer technology to help students finish learning tasks; for example, teachers introduce botanical concepts for identifying differences between plant species through field trips, which can help students to better understand and observe physical plants. However, conventional outdoor learning methods are time-consuming and labor-intensive for both teachers and students. Most outdoor learning approaches provide only one-way knowledge transmission in the real world and are less effective since the approach lacks meaningful interaction with students during the knowledge transfer phase (C. C. Chen \& Huang, 2012; Chin et al., 2018).

The application of handheld devices to support authentic learning activities, called mobile learning, has become a popular research topic in recent years (Y. S. Chang, 2019; Chiang et al., 2014a, 2014b; Hwang $\& \mathrm{Wu}, 2014)$. The mobile-based learning system provides opportunities for students to learn without the limitations of time or place and is a useful teaching tool to solve the problems encountered during traditional outdoor learning in physical environments. Although such learning systems have reported positive effects in many different educational domains, a few studies have also found negative effects (e.g., cognitive problems, distraction) arising from the use of mobile technologies in physical environments (Chu, 2014; Hwang et al., 2016; Liu et al., 2012). Therefore, it is worthy to investigate how to use specific learning strategies and tools to attract students' interest and promote their personal knowledge in mobile learning environments (S. C. Chang \& Hwang, 2018; Moorthy et al., 2019).

\section{AR}

$\mathrm{AR}$ is a $3 \mathrm{D}$ technology that enables the integration of real-world experiences with digital information (Hwang et al., 2016; Ibáñez \& Kloos, 2018). Virtual objects are superimposed on top of the real-world environment, enabling visualisation of invisible concepts or events through the use of technology (Wu et al., 2013). Chiang et al. (2014a, 2014b) explained that AR technology can provide users with a more realistic and immersive experience by merging the physical and digital worlds in real time. This means that AR technology is able to incorporate virtual objects into real-world environments and provide real-time interactions between users and the digital content to enhance their sensory experience (Andújar et al., 2011; Azuma, 1997; Ibáñez \& Kloos, 2018; Pejoska-Laajola et al., 2017; Serio et al., 2013).

In recent years, AR technology has become an important issue that attracts widespread attention and discussion in educational fields. The main factors of AR acceptance in educational fields include the availability of low-cost handheld devices that have innovative features to enable the deployment of ARbased applications (Ibáñez \& Kloos, 2018). Many studies have documented the potential of employing AR to assist students to better acquire knowledge and improve learning outcomes in real-world environments compared to traditional teaching methods (Ibáñez \& Kloos, 2018; Pejoska-Laajola et al., 2017). For example, Irizarry et al. (2013) proposed a mobile AR tool to improve construction practices and increase efficiency in facility management. Hwang et al. (2016) proposed a mobile AR educational game to provide effective learning support for in-field observation activities in elementary school ecology courses. Chu et al. (2019) developed an AR learning approach to improve students' learning achievements and reduce their cognitive load when they absorb architectural knowledge and historical theories. Ibáñez and Kloos (2018) discussed trends in AR applications for science, technology, engineering and mathematics learning; they also pointed out that AR will be further utilised in science, technology, engineering and mathematics, and in the increase of spatial ability, practical skills, conceptual understanding and scientific inquiry learning.

Although studies have indicated that AR seems to constitute a portable classroom for learning anytime or right next to the subject, some researchers have also pointed out that such technology may impose an extra cognitive load on students (M.-P. Chen et al., 2019; Diao \& Shih, 2019). For example, Cheng et al. (2013) suggested that students might experience cognitive overload in an AR learning environment due to task complexity. Chu et al. (2019) asserted that students' learning effects may not be increased without proper tools or strategies, even if new technologies such as AR systems are applied in physical environments. 
Most AR-based mobile learning systems have been applied towards foreign language learning, environmental and ecological education, engineering and computer education (Hwang \& Wu, 2014). Bacca et al. (2014) reviewed 32 studies regarding AR technology from 2003 through 2013, and found that science learning (e.g., lab experiments, ecology, mathematics, geometry) and humanities and arts (e.g., language learning, visual arts, painting appreciation) were the education fields in which AR was applied the most. Only a few studies have focused on how AR-based mobile systems work in cultural heritage-based programs (Ibáñez \& Kloos, 2018; Wu et al., 2013). Those cultural heritage education courses require exploration of cultural heritage, as well as the conservation and promotion of historical sites; thus, educators usually adopt field trips or outdoor experiences in their course curriculum. Such courses could benefit from the addition of AR-based mobile learning systems to help students understand past and present cultures during authentic learning activities (Chin et al., 2019; Chu et al., 2019).

Therefore, this study developed an AR-based mobile touring system support for students in university-level cultural heritage courses and further investigated whether AR technology has the potential for improving students' learning efficiency in real-world learning contexts.

\section{Research purpose}

This study aimed to investigate the effect of applying AR technology, which is known to be effective in mobile learning environments. To accomplish this, we developed the AR-based mobile touring system for an authentic learning activity. Such a learning approach is effective in real-world environments in comparison to traditional outdoor instruction (Chin et al., 2018; Chin et al., 2019; Ibáñez et al., 2014). In line with the aforementioned research purpose, we analysed the learning performance and interest of students who participated in the learning activity to verify the usefulness of AR technology. This study also investigated the possibility that AR technology can motivate students and increase their learning performance. The research questions are outlined, as follows, and the conceptual framework is illustrated in Figure 1.

(1) Can the AR-based mobile touring system improve the comprehension and retention of students and analyse the dimensions of the learning performance in comparison with the conventional mobile touring system?

(2) Can the AR-based mobile touring system increase students' learning interest (latent interest, actualised interest, text-based interest, task-based interest, knowledge-based interest and total interest) in comparison with the conventional mobile touring system?

(3) What critical learning interest factors are affected by the AR-based mobile touring system?

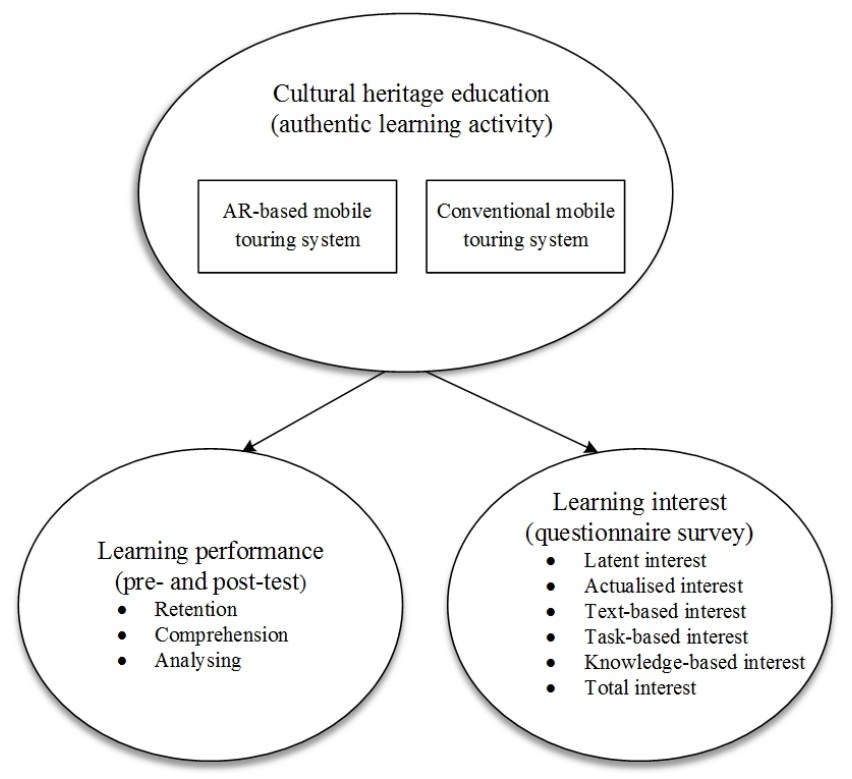

Figure 1. The conceptual framework of the research questions 


\section{Development of an AR-based mobile touring system}

In this study, we developed the AR-based mobile touring system through use of the Unity and DSpace servers; it is compatible with Android-based smartphone platforms. In this study, the authentic learning activities are related to cultural heritage education consisting of six historic sites, in which different types of historical buildings and their cultural context are introduced. A location-aware real-world learning environment is established through the use of a global positioning system (GPS) and mobile network technologies. When learning in this environment, each student is guided to find the target physical objects by detecting their location and display the corresponding learning materials on their mobile phones preinstalled with the proposed system.

\section{System framework and functions}

Figure 2 shows the structure of the AR-based mobile touring system, which is developed in the form of an authentic learning activity. It consists of a learning system interface, a GPS mechanism, a materials display mechanism, a time-map mechanism and an AR guidance mechanism. Moreover, we also established three databases - a personal profile database, a learning material database and an AR materials database to provide learning support for individual students.

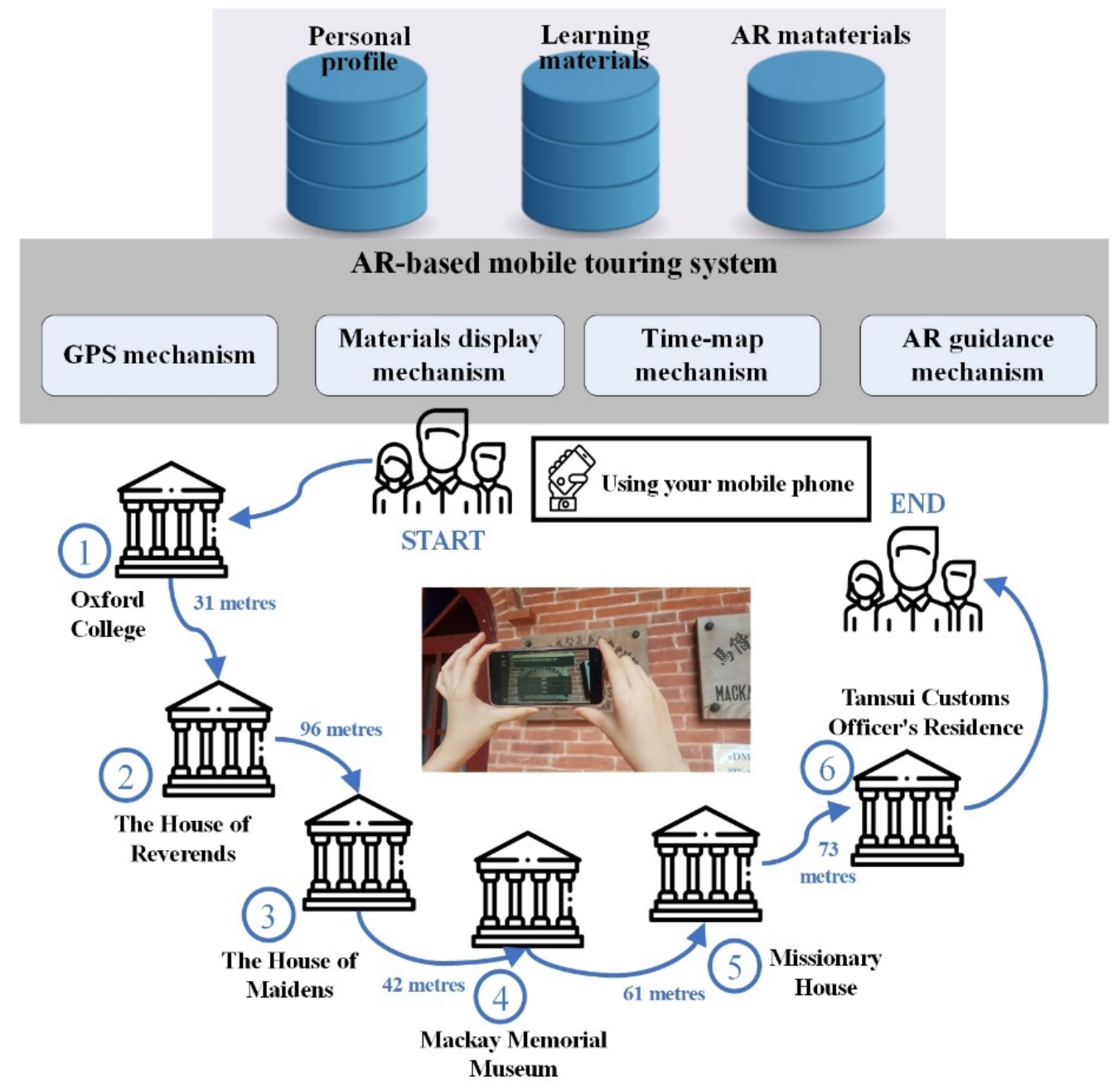

Figure 2. System structure of the AR-based mobile touring system

The learning system interface was designed for presenting the system functions and multimedia learning content. The basic process of the learning activity involves asking students to visit several sequential locations (i.e., the Taiwanese Oxford College, the House of Reverends, the Mackay Memorial Museum, 
the Missionary House), each of which represents a cultural heritage site. Once students arrive at the designated position, they can access the relevant learning content and obtain the corresponding AR materials via the proposed system. Students also need to move around the real-world environment and observe the corresponding physical objects during the learning process.

The GPS mechanism is used to display the relevant positioning of the historical buildings on an electric map; it enables students to see their current position relative to the learning target. The materials display mechanism is used to provide the instructional content and multimedia materials on the phone screen; students can obtain further learning information related to learning targets during the learning activity. The time-map mechanism is used to provide a construction timeline of cultural heritage sites on the electric map, which enables students to understand the development process of the learning targets in sequence. The AR guidance mechanism is used to superimpose virtual questions and supplementary materials on top of the real-world environment, which guides students to make further observations in the field when they fail to correctly answer a question related to the learning target.

\section{Interface of the AR-based mobile touring system}

Figure 3 shows the main system interfaces consisting of the AR guidance button, time-map button and GPS button. During the outdoor learning process, students must start up the pre-installed app on their mobile devices to open the main menu of the proposed system (see Figure 3(a)). First, students can press the timemap button to open the timeline of the past 200 years; the system will show the electric map with a scrollable list of relevant years where information was available. When students select one of the displayed years from the electric map, the system provides information regarding the architecture of the corresponding cultural heritage sites during the selected year (see Figure 3(b)).

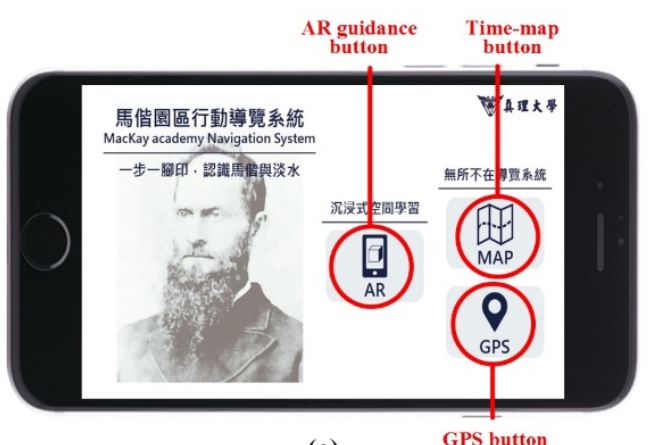

(a)

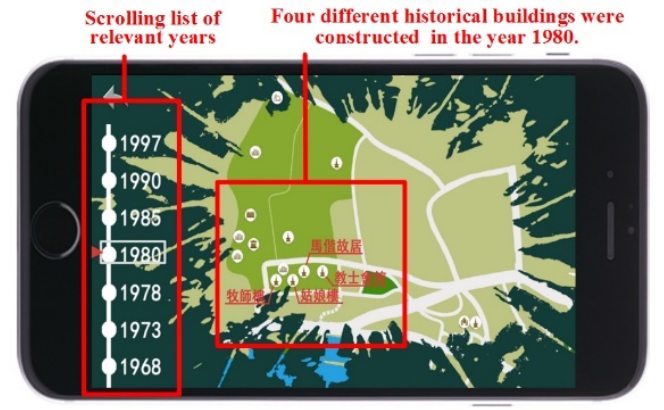

(b)

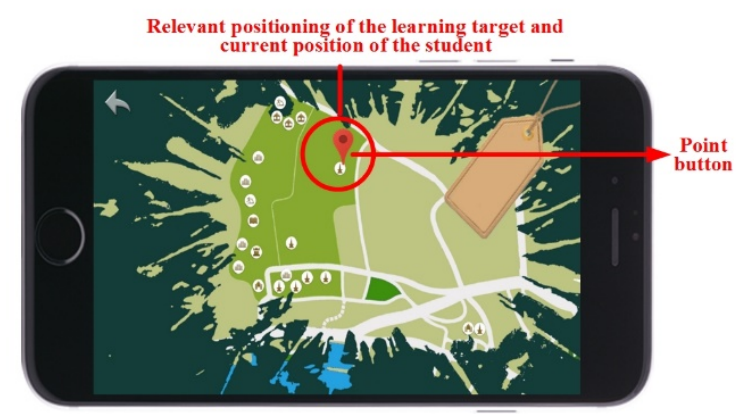

(c)

Figure 3. User interface of the time-map and GPS mechanisms

Secondly, students can tap the GPS button to open the electric map, which shows the relevant positioning of all the cultural heritage sites and the current position of students (see Figure 3(c)). This map can guide students to the historical building that they are interested in learning more about. Once students arrive at a specific location in the physical environment, they can press the Point button to access relevant digital learning materials displayed on the phone screen. Figure 4(a) shows an example of the instructional content (including narrative text and pictures) regarding Oxford College, a Taiwanese cultural heritage site dating back to 1882. Students are then able to swipe the touch screen back and forth to move through the relevant pictures presented by the system, allowing for more control over their learning pace. 


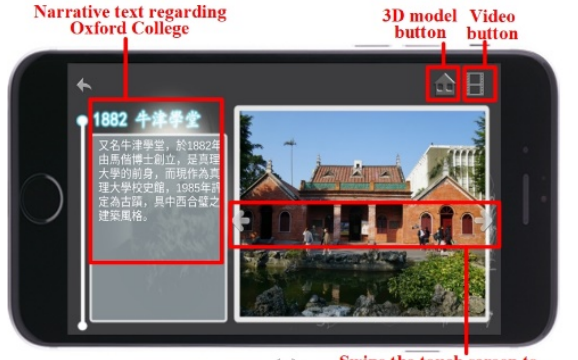

Swipe the touch screen to
move the relevant pictures

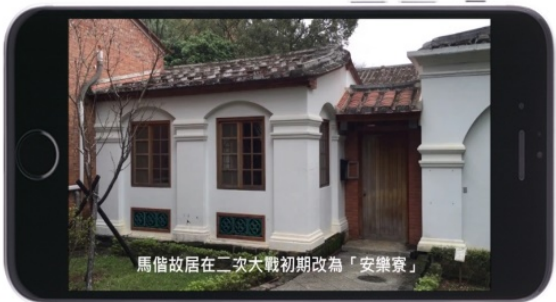

(b)

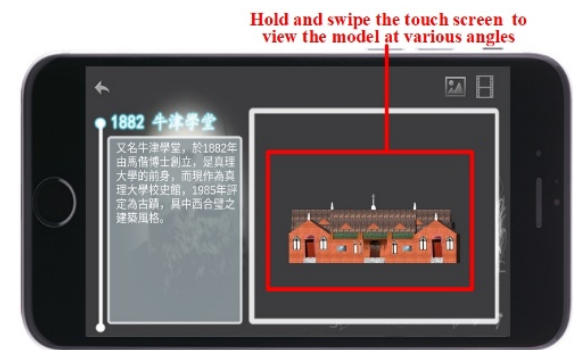

(c)

Figure 4. User interface of the materials display mechanism

Moreover, students are able to tap the Video button to see the video file associated with the learning target (see Figures 4(a) and 4(b)), or select the 3D model button to display the relevant 3D virtual object and view a digital model of the building (see Figures 4(a) and 4(c)). This digital model enables students to use holdand-swipe movements on the touch screen of the mobile phone to view the model from various angles. Thus, through the use of the proposed system, students can carefully observe 3D virtual objects and compare those objects with the corresponding learning targets seen in the real-world environment.

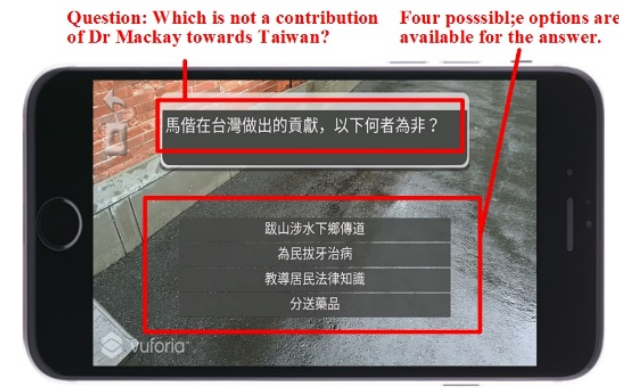

(a)

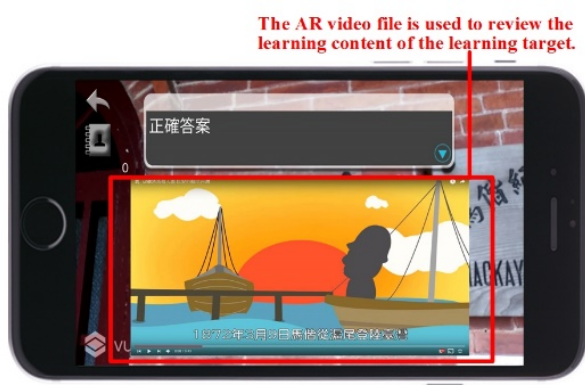

(b)

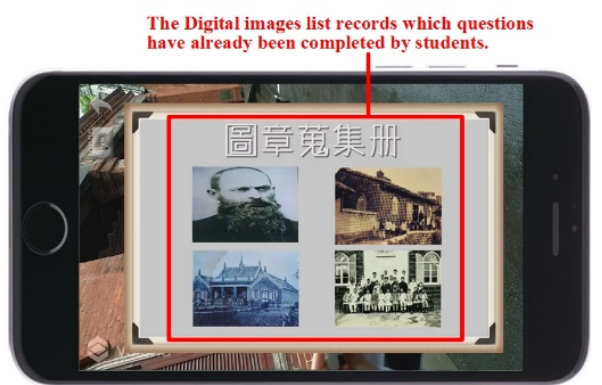

(c)

Figure 5. User interface of the AR guidance mechanism

When students have finished reading the digital learning materials, they can tap the AR guidance button to scan a designated physical object (see Figure 3(a)); the system then accesses the corresponding AR materials about the learning target from the remote database. Figure 5(a) shows an example of the AR question; it asks students to answer the topic related to the contributions of Dr Mackay towards Taiwan. 
The AR question can be a multiple-choice question of the learning target in the field. If students fail to answer the AR question, the system provides the AR video file, which enables students to review the learning content of the learning target and make further observations on the details of the learning target (see Figure 5(b)). Following that, students are asked to answer the AR question again. Once students answer the AR question correctly, the system provides an AR list of images that represent relevant learning targets to remind students which learning activities have completed, and further to monitor their own progress (see Figure 5(c)).

\section{Experiment design}

To evaluate the efficacy of AR technology, we conducted an experiment to compare the learning outcomes of the students who learned with the AR-based mobile touring system and those who learned with the conventional mobile touring system. The physical environment consists of 6 historic sites located in northern Taiwan. The authentic learning activity was part of the regular cultural heritage course in the target school. Students in this course must learn about the broader context of the historic sites presented, including the background history of buildings, advancements in architecture design concepts over time and the aesthetic principles of architecture.

\section{Participants}

We conducted the experiment during the period from 1 April 2019 through to 30 April 2019 at Aletheia University in northern Taiwan. A total of 72 first-year students (aged 18-20; 34 males and 38 females) from two different classes of the cultural heritage course at the targeted school were invited to participate in this study. The two classes were taught by the same teacher, who had over 10 years of teaching experience at the school and exhibited high-level proficiency in conventional classroom teaching methods. One class was randomly assigned as the control group $(\mathrm{N}=35,16$ males and 19 females), while the other class was designated as the experimental group $(\mathrm{N}=37,18$ males and 19 females $)$. Both classes had the same learning content during the learning activity. No students were privy to the instructional materials in advance.

The control group was required to attend classes using the conventional mobile touring system, where they were provided with a mobile learning system without AR guidance mechanism, which introduced each of the historical buildings along with a variety of related relics through the use of images, video, text. The experimental group was instructed to use the AR-based mobile touring system to learn the same course materials in a real-world setting outside of the classroom. Moreover, all the student participants were required to read and sign an informed consent form to indicate their willingness to participate in the study with permission; they could withdraw from the study any time they preferred.

\section{Measuring tools}

The measuring tools included learning achievement tests and a questionnaire for assessing student performance and learning interest. Since this study took place at the university in northern Taiwan, we developed the questions of all the measuring tools in Chinese language. First, to evaluate student learning performance, we developed the pre- and post-tests to gauge the level of knowledge that the participants had on the historical buildings before and after participating in the experiment. The pre-test served as a benchmark to determine the extent of background knowledge participants already had prior to the learning activity. The post-test consisted of both retention and comprehension questions. The full score on either the pre- or post-test was 100 points. To ensure the reliability and validity of this study, two experienced teachers checked all research processes. Moreover, all of the questions (the pre-test, the post- test and the questionnaire survey) were checked by those teachers for expert validity, which ensured the accuracy of the course content and materials.

There were 25 multiple-choice retention questions, each with four options for the answer, with a total score of 50. The aim of the retention questions was to determine if students could remember historical facts related to the buildings, important historical events of the buildings, specific construction techniques and building materials. For example, students might be asked, "Who is responsible for building the Missionary House?" with possible answer options available below the question, "A. Dr. George Leslie Mackay", "B. Rev. William Gauld”, “C. Miss Hannah Connell”, "D. Rev. Thurlow Fraser"; or "Which architectural style was used for the exterior of the House of Reverends?" with answer options provided such as, "A. The 
dome-shaped style of Roman buildings", "B. Spanish style colonial architecture", “C. Modernist architecture", "D. Residential bungalow architecture",

In addition to the multiple-choice questions, we used five open-ended questions to measure comprehension, with 50 being a perfect score. This question type measured whether students could correctly describe the construction techniques described during the learning activities and the contribution of these buildings to Taiwanese culture. Participants were also challenged to elaborate on the historical relationship between the buildings. For example, students would be provided with a photograph of Mackay Memorial Museum and asked: "Please write down the name and age of this building, and also provide information to explain the purpose of this building and what it has been used for. What are the aesthetic principles and architectural design concepts behind the construction of this building?"

Second, we developed the questionnaire on students' learning interest by referring to the definition of personal interest and situational interest developed by Schraw and Lehman (2001). Personal interest is topic specific, persists over time and includes latent interest and actualised interest (Krapp et al., 1992; Schraw, 1994). Latent interest is regarded as a long-term orientation towards a particular topic, which is a dispositional state that influences cognitive engagement, whereas actualised interest is regarded as a topicspecific motivational state that determines individual engagement style in a learning activity (Schiefele, 1996, 1999; Schraw, 1994, 1998). Situational interest concerns information that is of temporary value, environmentally activated and context-specific, which includes text-based interest, task-based interest and knowledge-based interest (Hidi \& Anderson, 1992; Schraw \& Lehman, 2001). Text-based interest is regarded as aspects of the text used to affect learners' interest; task-based interest concerns task manipulations or encoding instructions that can increase learners' interest; knowledge-based interest is regarded as aspects of the learner's knowledge base used to enhance learners' interest (Schraw \& Lehman, 2001).

In this study, we adopted the questionnaire on student learning interest to measure the dimension of interest of students in the experimental and control groups. Five factors were measured in the questionnaire: latent interest, actualised interest, text-based interest, task-based interest and knowledge-based interest. It consists of 20 items on a conventional 5-point Likert-scale - five items for latent interest, three items for actualised interest, five items for text-based interest, three items for task-based interest and four items for knowledgebased interest, where Cronbach's alpha values were $0.82,0.79,0.81,0.83$ and 0.83 , respectively. These values show good reliability in internal consistency.

\section{Experiment procedure}

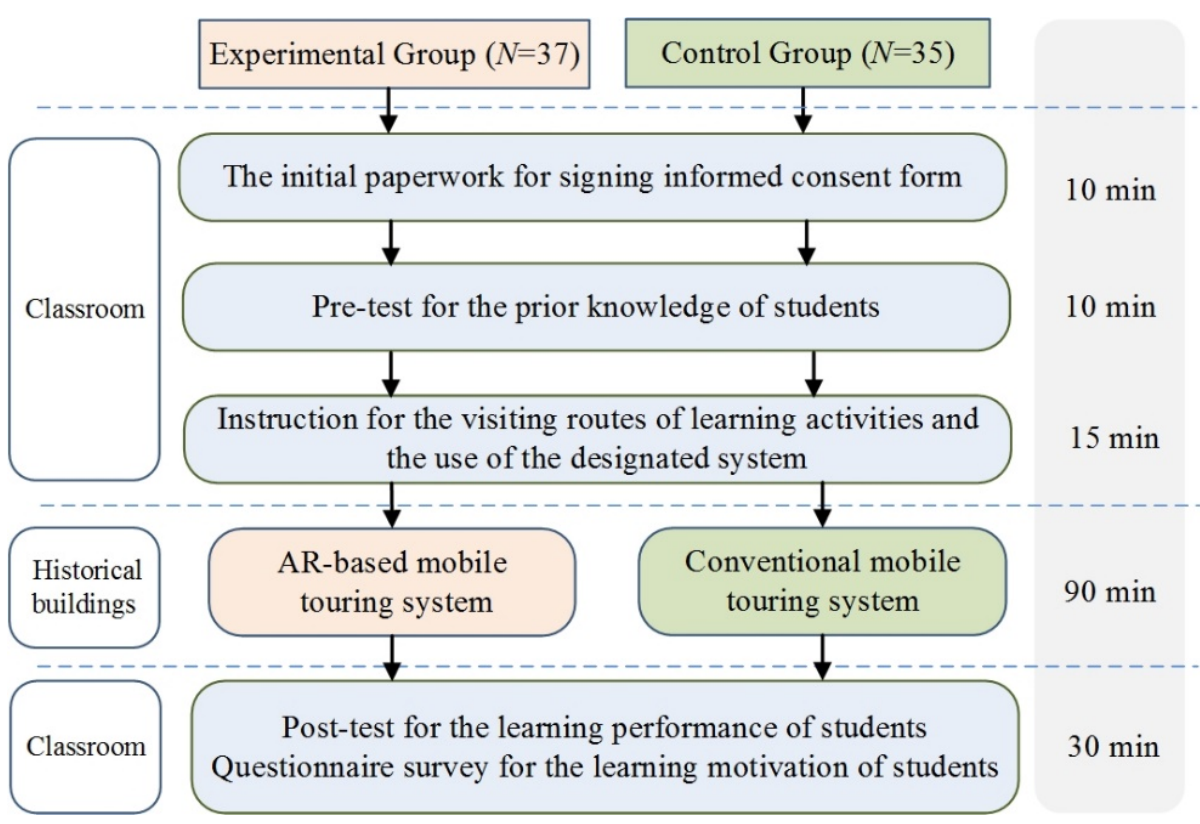

Figure 6. Experiment design 
Figure 6 shows the procedure of the experiment. At the beginning of the learning activity, the aim of the learning task was introduced to all the student participants; each student was given the chance to review and read the informed consent form that indicated they were willing to participate in this study. Moreover, an additional pre-test was carried out to assess all the student participants' prior knowledge on the course materials used. Following the pre-test, both groups were briefed with the visiting routes of learning activities, and then the experimental group participants were instructed to use the AR-based mobile touring system to accomplish the learning goals; on the other hand, the control group participants used the conventional mobile touring system without the AR guidance mechanism. Both versions of the learning activity consisted of the same background story, learning missions and instructional content.

The time for all student participants to complete their learning missions was 90 minutes. All six historical buildings used in the activity of this study were located within a walking distance of about 5-10 min from the college. Every building selected for inclusion in our study was selected due to its rich and varied history, with a minimum age of construction dating back 100 years or more. During the learning activity, students in both groups were given $10 \mathrm{~min}$ at each historical site and permitted to use only the learning method assigned to their group. After the 10-min period, all participants had to move to the next station to stay on track. Each group also had three researchers accompanying them, who served as timekeepers while observing student behaviour and overseeing the learning activity as a whole.

After completing the learning activity, the student participants of both groups took the post-test to measure any change in their learning performance and filled out the post-questionnaire to reflect on their personal learning interest. Finally, we conducted a statistical analysis to generate the result of quantification.

\section{Data analysis}

The Statistical Package for Social Science tool was used to analyse the experimental data collected during this study. The independent samples t tests and one-way ANCOVA results were used to evaluate the preand post-test scores and the learning interest response ratings provided by participants. For our study, the independent variable was defined as the two learning methods used by the experimental and control groups (i.e., the AR-based mobile touring system and the conventional mobile touring system). The dependent variables in our study were students' overall learning performance and their learning interest. All statistical analyses for this study were conducted using a two-sided alpha level value of 0.05 .

\section{Results}

\section{Analysis of learning achievement}

Table 1

Descriptive data and independent sample t tests of the pre-test results

\begin{tabular}{llllll}
\hline Question type & Learning group & $N$ & Mean & SD & $t$ value \\
Retention & Experimental group & 37 & 26.81 & 6.10 & -0.86 \\
& Control group & 35 & 28.34 & 8.79 & \\
Comprehension & Experimental group & 37 & 10.05 & 4.09 & -0.20 \\
& Control group & 35 & 10.26 & 4.43 & \\
Total score & Experimental group & 37 & 36.86 & 9.47 & -0.71 \\
& Control group & 35 & 38.60 & 11.35 & \\
\hline
\end{tabular}

To evaluate the effectiveness of the system, we conducted an experiment on a college-level cultural heritage course in Taiwan. Independent sample $t$ tests were used to quantify the prior knowledge of the two groups related to the target topic of this study. As shown in Table 1, the comparative results of the pre-test scores revealed that no matter whether retention-type questions $(t=-0.86, p>0.05)$ or comprehension-type questions $(t=-0.20, p>0.05)$, there was no significant difference $(t=-0.71, p>0.05)$ between the two groups before performing the experimental activity. 
Descriptive data and one-way ANCOVA of the post-test results

\begin{tabular}{llllllll}
\hline Question type & Learning group & $N$ & Mean & SD & $\begin{array}{l}\text { Adjusted } \\
\text { mean }\end{array}$ & $\begin{array}{l}\text { Std } \\
\text { error }\end{array}$ & $F$ \\
\hline Retention & Experimental group & 37 & 45.03 & 6.47 & 45.17 & 1.11 & $7.90^{* *}$ \\
& Control group & 35 & 40.83 & 7.20 & 40.68 & 1.14 & \\
Comprehension & Experimental group & 37 & 31.19 & 7.99 & 31.22 & 1.22 & 0.92 \\
& Control group & 35 & 29.57 & 7.03 & 29.54 & 1.26 & \\
Total score & Experimental group & 37 & 70.40 & 12.13 & 76.54 & 1.93 & $5.46^{*}$ \\
& Control group & 35 & 76.22 & 12.54 & 70.05 & 1.99 & \\
\hline
\end{tabular}

${ }^{*} p<0.05 .{ }^{* *} p<0.01$

Even though the pre-test scores of this study were not significantly different between the two groups, there were slight variations in the dimensions of retention and comprehension. In order to maintain statistically equal groups, one-way ANCOVA analysis was used to compare the differences between the post-test scores of the two groups. ANCOVA evaluates whether the means of a dependent variable are equal across the levels of independent variables, while statistically controlling the effects of other covariates variables. To promote the accuracy of the experimental results of ANCOVA analysis, the pre-test scores are taken as the covariate variable, the post-test scores as the dependent variable, and the learning method assigned to the two groups as the independent variable.

As shown in Table 2, the results indicate that the experimental group students had better learning achievement than those who were taught through the conventional mobile touring system $(F=5.46, p<$ $0.05)$. This analysis also found significant differences in retention-type questions $(F=7.90, p<0.01)$ between the two groups, but there were no significant differences found in comprehension-type questions $(F=0.92, p>0.05)$. This analysis confirmed that the AR-based mobile touring system could enhance the learning performance of students more than the conventional mobile touring system. In addition, the Cronbach's alpha value of the post-test scores was 0.87 , indicating high reliability.

\section{Analysis of learning interest}

For our study, independent sample $t$ tests were conducted to evaluate the experimental results obtained from the questionnaire survey of both groups. This analysis focused on the results specifically related to learning interest. In this study, five learning interest factors were measured in the questionnaire. Table 3 shows the $t$ test results of the learning interest ratings of the two groups, indicating significant difference in learning interest $(t=1.90, p>0.05)$. The experimental result showed that the students who learned with the AR-based mobile touring system were able to improve their learning interest more than those who learned with the conventional mobile touring system. This finding suggests the potential of AR technology to motivate learning due to its real-time interaction and enjoyable experience (Cascales-Martínez et al., 2017; Chin et al., 2019; Chu et al., 2019; McMahon et al., 2016; Yilmaz, 2016).

Table 3

Independent sample t tests results from the questionnaire focusing on learning interest of the two groups

\begin{tabular}{|c|c|c|c|c|c|}
\hline Factor & Learning group & $N$ & Mean & $S D$ & $t$ value \\
\hline \multirow[t]{2}{*}{ Latent interest } & Experimental group & 37 & 3.73 & 0.90 & 1.85 \\
\hline & Control group & 35 & 3.74 & 0.78 & \\
\hline \multirow{2}{*}{ Actualised interest } & Experimental group & 37 & 3.76 & 0.67 & $0.89 *$ \\
\hline & Control group & 35 & 3.60 & 0.82 & \\
\hline \multirow[t]{2}{*}{ Text-based interest } & Experimental group & 37 & 4.01 & 0.52 & 1.75 \\
\hline & Control group & 35 & 3.78 & 0.58 & \\
\hline \multirow[t]{2}{*}{ Task-based interest } & Experimental group & 37 & 3.81 & 0.63 & $1.58^{*}$ \\
\hline & Control group & 35 & 3.56 & 0.71 & \\
\hline \multirow[t]{2}{*}{ Knowledge-based interest } & Experimental group & 37 & 3.69 & 0.44 & 0.33 \\
\hline & Control group & 35 & 3.64 & 0.71 & \\
\hline \multirow[t]{2}{*}{ Total score } & Experimental group & 37 & 3.81 & 0.31 & $1.90^{*}$ \\
\hline & Control group & 35 & 3.61 & 0.56 & \\
\hline
\end{tabular}

$* p<0.05$ 
This study found significant differences in the assessment of the actualised interest factor and the taskbased interest factor between the two groups from the questionnaire survey. The factor of actualised interest is related to how much the student wants to seek challenges and continue to make an effort in the face of failure during learning activities (Schiefele, 1991). The experimental results related to the actualised interest factor $(t=0.89, p<0.05)$ indicated that the proposed system used by the experimental group effectively encouraged students to attempt the learning tasks in comparison to the conventional mobile touring system used by the control group. The factor of task-based interest measures how to highlight learning information so that it is more accessible to students and make the entire learning content more cohesive (Hidi \& Anderson, 1992). The analysis of the qualitative results related to the task-based interest factor $(t=1.58, p$ $<0.05)$ indicated that students assigned to the experimental group felt the learning content accessed through the use of the AR-based mobile touring system to be more coherent and readable. All the scores obtained through the questionnaire survey were evaluated for Cronbach's alpha reliability, and the result of 0.83 indicated that the instrument used for assessing the results from the questionnaire survey was good and highly reliable.

\section{Discussion and limitations}

In this study, the experiment results indicated that the AR-based mobile touring system was helpful for students in memorising and integrating new knowledge through their learning activities, while further facilitating students' higher learning effectiveness. The experimental results of this study also showed that the students who learned with the AR-based mobile touring system showed greater learning interest; meanwhile, the positive impact of the proposed system on students' actualised interest and task-based interest factors provided particularly encouraging results for future applications in the field of education. Some students in the experimental group reported that the AR guidance mechanism of the proposed system was very interesting and able to attract their attention to the AR questions and AR videos. Those students also indicated that the AR guidance mechanism was particularly useful because it provided opportunities for them to recall the learning content and observe the corresponding physical object at the same time, thus enhancing their overall learning impression. This may be the reason that students in the experimental group achieved better learning performance and greater interest than students in the control group.

Several studies have shown that using AR technology provides opportunities for students to increase their learning knowledge and further enhance their engagement and achievement (Bacca et al., 2014; Diao \& Shih, 2019; Hwang et al., 2016; Ibáñez \& Kloos, 2018); for example, Ibanez and Kloos (2018) found that AR technology can be effective in promoting students' learning benefits and development. Yu and his colleagues (2019) also proved that AR-based online wearable guidance systems can improve students' situational interest and learning achievement. According to those studies, AR can be regarded as a useful tool for learning, as it is able to attract students' attention and promote their engagement and interest in educational activities (Serio et al., 2013); however, only a few recent studies have focused on how ARbased mobile systems work in cultural heritage-based programs (Ibáñez \& Kloos, 2018; Wu et al., 2013). To fill this gap, this study developed an AR-based mobile touring system, which was used to support students enrolled in university-level cultural heritage courses; this study also confirmed that AR technology can improve university students' learning performance and interest, as compared with the conventional mobile touring system.

Although the AR-based mobile touring system was effective in helping students improve their learning performance in a cultural heritage course, there are still some limitations to this study. First, the proposed system is compatible only with Android-based smartphone platforms and cannot be applied to other operating systems. Moreover, during the outdoor learning activity, we encountered technology limitations of wireless connectivity, such as failure in providing critical information regarding the correct position of the heritage sites and failure in displaying relevant AR videos onto the screen. To extend this approach to other applications, updated versions should contain technical advancements to enhance overall satisfaction and acceptability. Second, the multimedia materials provided by both systems related only to six historical buildings, and those materials did not contain the whole learning content of the outdoor learning activity. To extend the findings of this study to a course with a complete multimedia learning content, further studies are needed to validate the design for AR-based learning approaches. 


\section{Conclusion and implications}

This study proposed an AR-based mobile touring system for conducting authentic learning activities in cultural heritage courses. An experiment was conducted to evaluate the performance of the proposed system in a cultural heritage course at a Taiwanese university. The experimental results show that, in comparison with the conventional mobile touring system (without AR technology), the proposed system significantly improved students' learning achievements, especially with regards to learning content associated with retention. Moreover, this result shows that the proposed system significantly enhanced the learning interest of experimental group students, especially regarding their actualised interest and task-based interest factors. This means that the AR guidance mechanism of the proposed system might increase students' motivation during the learning process. In other words, with regards to learning interest, AR technology exhibits the ability to cultivate temporary situational interest during authentic learning activities, which increases students' long-term personal interest towards course materials. This situation also has direct bearing on the positive correlation with the memorising dimension of learning performance; hence, if the situational interest of students can be raised, the memorising dimension of learning achievement may also be increased.

Therefore, it would be useful to explore the possibility of extending the application of our proposed system to other types of outdoor learning activities, such as social studies courses and environmental protection courses. It could be interesting to adopt a new technology as a teaching tool for students to engage in learning activities in person; meanwhile, it would also provide valuable opportunities for learning experiences and achievement for students. In addition, it would be a major oversight to ignore the personal and unique learning needs of students (e.g., cognitive styles or learning patterns) when investigating the effectiveness of the proposed system. To encourage the accurate analysis of students' learning interest, the learning interest survey of the pre-test should be considered when conducting the next experimental procedure. Further studies are still needed to accurately evaluate the findings of this study with regard to using AR technology for the personalised learning of students and to investigate whether AR technology can solve the drawback of outdoor teaching issues, such as one-way knowledge transmission process and less effective interaction with students.

\section{Acknowledgements}

We are especially grateful to undergraduate student Ya-Chuan Kao, Department of Digital Humanities at Aletheia University, for supporting the outdoor learning activity of this study. Moreover, this project was financially sponsored by the Taiwanese Government's Ministry of Science and Technology, under grant numbers MOST 108-2511-H-156-001-MY2 and MOST 108-2745-8-156-001.

\section{References}

Aguayo, C., Cochrane, T., \& Narayan, V. (2017). Key themes in mobile learning: Prospects for learnergenerated learning through AR and VR. Australasian Journal of Educational Technology, 33(6), 2740. https://doi.org/10.14742/ajet.3671

Andújar, J. M., Mejías, A., \& Márquez, M. A. (2011). Augmented reality for the improvement of remote laboratories: an augmented remote laboratory. IEEE Transactions on Education, 54(3), 492-500. https://doi.org/10.1109/TE.2010.2085047

Azuma, R. T. (1997). A survey of augmented reality. Presence-Teleoperators and Virtual Environments, 6(4), 355-385. https://doi.org/10.1162/pres.1997.6.4.355

Bacca, J., Baldiris, S., Fabregat, R., Graf, S., \& Kinshuk. (2014). Augmented reality trends in education: A systematic review of research and applications. Journal of Educational Technology \& Society, 17(4), 133-149. https://doi.org/10.2307/jeductechsoci.17.4.133

Bujak, K. R., Radu, I., Catrambone, R., Macintyre, B., Zheng, R., \& Golubski, G. (2013). A psychological perspective on augmented reality in the mathematics classroom. Computers \& Education, 68, 536-544. https://doi.org/10.1016/j.compedu.2013.02.017

Bursztyn, N, Shelton, B., Walker, A., \& Pederson, J. (2017). Increasing undergraduate interest to learn geoscience with GPS-based augmented reality field trips on student's own smartphones. GSA Today, 27(6), 4-10. https://doi.org/10.1130/GSATG304A.1 
Cascales-Martínez, A., Martínez-Segura, M. J., Pérez-López, D., \& Contero, M. (2017). Using an augmented reality enhanced tabletop system to promote learning of mathematics: A case study with students with special educational needs. Eurasia Journal of Mathematics, Science and Technology Education, 13(2), 355-380. https://doi.org/10.12973/eurasia.2017.00621a

Chang, S. C., \& Hwang, G. J. (2018). Impacts of an augmented reality-based flipped learning guiding approach on students' scientific project performance and perceptions. Computers \& Education, 125, 226-239. https://doi.org/10.1016/j.compedu.2018.06.007

Chang, Y. S. (2019). The mediating role of motivation for creative performance of cloud-based mlearning. Australasian Journal of Educational Technology, 35(4), 34-45. https://doi.org/10.14742/ajet.4418

Chen, C. C., \& Huang, T. C. (2012). Learning in a u-museum: Developing a context-aware ubiquitous learning environment. Computers \& Education, 59(3), 873-883. https://doi.org/10.1016/j.compedu.2012.04.003

Chen, M.-P., Wang, L.-C., Lin, S.-Y., Zou. D., Xie, H., \& Tsai, C.-C. (2019). Enhancing contextualized learning via AR. In Proceedings of the 8th International Congress on Advanced Applied Informatics (pp. 286-289). IEEE. https://doi.org/10.1109/IIAI-AAI.2019.00064

Cheng, K. H., \& Tsai, C. C. (2013). Affordances of augmented reality in science learning: Suggestions for future research. Journal of Science Education and Technology, 22(4), 449-462. https://doi.org/10.1007/s10956-012-9405-9

Chiang, T. H. C., Yang, S. J. H., \& Hwang, G. J. (2014a). An augmented reality-based mobile learning system to improve students' learning achievements and motivations in natural science inquiry activities. Journal of Educational Technology \& Society, 17(4), 352-365. http://www.jstor.org/stable/jeductechsoci.17.4.352

Chiang, T. H. C., Yang, S. J. H., \& Hwang, G. J. (2014b). Students' online interactive patterns in augmented reality-based inquiry activities. Computers \& Education, 78, 97-108. https://doi.org/10.1016/j.compedu.2014.05.006

Chin, K. Y., Lee, K. F., \& Chen, Y.-L. (2018). Using an interactive ubiquitous learning system to enhance authentic learning experiences in a cultural heritage course. Interactive Learning Environments, 26(4), 444-459. https://doi.org/10.1080/10494820.2017.1341939

Chin, K. Y., Wang, C.-S., \& Chen, Y.-L. (2019). Effects of an augmented reality-based mobile system on students' learning achievements and motivation for a liberal arts course. Interactive Learning Environments, 27(7), 927-941. https://doi.org/10.1080/10494820.2018.1504308

Chittaro, L., \& Ranon, R. (2007). Web3D technologies in learning, education and training: Motivations, issues, opportunities. Computers \& Education, 49(1), 3-18. https://doi.org/10.1016/j.compedu.2005.06.002

Choi, B., \& Baek, Y. (2011). Exploring factors of media characteristic influencing flow in learning through virtual worlds. Computers \& Education, 57(4), 2382-2394. https://doi.org/10.1016/j.compedu.2011.06.019

Chu, H. C. (2014). Potential negative effects of mobile learning on students' learning achievement and cognitive load-A format assessment perspective. Journal of Educational Technology \& Society, 17(1), 332-344. http://www.jstor.org/stable/jeductechsoci.17.1.332

Chu, H. C., Chen, J. M., Hwang, G. J., \& Chen, T. W. (2019). Effects of formative assessment in an augmented reality approach to conducting ubiquitous learning activities for architecture courses. Universal Access in the Information Society, 18(2), 221-230. https://doi.org/10.1007/s10209-0170588-y

Chu, H. C., Chen, J. M., Yang, K. H., \& Lin, C. W. (2016). Development and application of a repertory grid-oriented knowledge construction augmented reality learning system for context-aware ubiquitous learning. International Journal of Mobile Learning and Organisation, 10(1-2), 40-60. https://doi.org/10.1504/IJMLO.2016.076189

Chu, H. C., Hwang, G. J., Tsai, C. C., \& Tseng, Judy C. R. (2010). A two-tier test approach to developing location-aware mobile learning systems for natural science courses. Computers \& Education, 55(4), 1618-1627. https://doi.org/10.1016/j.compedu.2010.07.004

Diao, P. H., \& Shih, N. J. (2019). Trends and research issues of augmented reality studies in architectural and civil engineering education: A review of academic journal publications. Applied Sciences, 9(1840), 1-19. https://doi.org/10.3390/app9091840

Hidi, S., \& Anderson, V. (1992). Situational interest and its impact on reading and expository writing. In K. A. Renninger, S. Hidi, \& A. Krapp (Eds.), The role of interest in learning and development (1st ed., pp. 215-238). Lawrence Erlbaum Associates, Inc. 
Hwang, G. J., \& Chang, H. F. (2011). A formative assessment-based mobile learning approach to improving the learning attitudes and achievements of students. Computer \& Education, 56(4), 10231031. https://doi.org/10.1016/j.compedu.2010.12.002

Hwang, G. J., \& Wu, P. H. (2014). Applications, impacts and trends of mobile technology-enhanced learning: A review of 2008-2012 publications in selected SSCI journals. International Journal of Mobile Learning and Organisation, 8(2), 83-95. https://doi.org/10.1504/IJMLO.2014.062346

Hwang, G. J., Wu, P. H., Chen, C. C., \& Tu, N. T. (2016). Effects of an augmented reality-based educational game on students' learning achievements and attitudes in real- world observations. Interactive Learning Environments, 24(8), 1895-1906. https://doi.org/10.1080/10494820.2015.1057747

Ibáñez, M. B., \& Kloos, C. D. (2018). Augmented reality for STEM learning: A systematic review. Computers \& Education, 123, 109-123. https://doi.org/10.1016/j.compedu.2018.05.002

Ibáñez, M. B., Serio, Á. D., Villarán, D., \& Kloos, C. D. (2014). Experimenting with electromagnetism using augmented reality: Impact on flow student experience and educational effectiveness. Computers \& Education, 71, 1-13. https://doi.org/10.1016/i.compedu.2013.09.004

Irizarry, J., Gheisari, M., Williams, G., \& Walker, B. N. (2013). InfoSPOT: A mobile augmented reality method for accessing building information through a situation awareness approach. Automation in Construction, 33, 11-23. https://doi.org/10.1016/j.autcon.2012.09.002

Krapp, A. (1999). Interest, motivation and learning: An educational-psychological perspective. Journal of Psychology of Education, 14, 23-40. https://doi.org/10.1007/BF03173109

Krapp, A., Hidi, S., \& Renninger, K. A. (1992). Interest, learning, and development. In K. A. Renninger, S. Hidi, \& A. Krapp (Eds.), The role of interest in learning and development (1st ed., pp. 3-25). Lawrence Erlbaum Associates, Inc.

Liu, T. C., Lin, Y. C., Tsai, M. J., \& Paas, F. (2012). Split-attention and redundancy effects on mobile learning in physical environments. Computers \& Education, 58(1), 172-180. https://doi.org/10.1016/j.compedu.2011.08.007

McMahon, D. D., Cihak, D. F., Wright, R. E., \& Bell, S. M. (2016). Augmented reality for teaching science vocabulary to postsecondary education students with intellectual disabilities and autism. Journal of Research on Technology in Education, 48(1), 38-56. https://doi.org/10.1080/15391523.2015.1103149

Moorthy, K., Tsen, T. Y., Loh, C. T., \& Vikniswari, V. K. (2019). Habit and hedonic motivation are the strongest influences in mobile learning behaviours among higher education students in Malaysia. Australasian Journal of Educational Technology, 35(4), 174-191. https://doi.org/10.14742/ajet.4432

Nagata, J. J., Abad, F. M., Giner, J. G. B., \& Peñalvo, F. J. G. (2017). Augmented reality and pedestrian navigation through its implementation in m-learning and e-learning: Evaluation of an educational program in Chile. Computers \& Education, 111, 1-17. https://doi.org/10.1016/j.compedu.2017.04.003

Ogata, H., \& Yano, Y. (2004). Context-aware support for computer-supported ubiquitous learning. Proceedings of IEEE International Workshop on Wireless and Mobile Technologies in Education 2004, 27-34. https://doi.org/10.1109/WMTE.2004.1281330

Pejoska-Laajola, J., Reponen, S., Virnes, M., \& Leinonen, T. (2017). Mobile augmented communication for remote collaboration in a physical work context. Australasian Journal of Educational Technology, 33(6), 11-26. https://doi.org/10.14742/ajet.3622

Schiefele, U. (1991). Interest, learning, and motivation. Educational Psychologist, 26(3-4), 299-323. https://doi.org/10.1207/s15326985ep2603\&4_5

Schiefele, U. (1996). Topic interest, text representation, and quality of experience. Contemporary Educational Psychology, 21(1), 3-18. https://doi.org/10.1006/ceps.1996.0002

Schiefele, U. (1999). Interest and learning from text. Scientific Studies of Reading, 3(3), 257-279. https://doi.org/10.1207/s1532799xssr0303 4

Schraw, G. (1994). A matter of interest: The role of interest in learning and development [Review of the book $A$ matter of interest: The role of interest in learning and development, by K. A. Renninger, S. Hidi, \& A. Krapp, Eds.]. Applied Cognitive Psychology, 8(5), 526-528. https://doi.org/10.1002/acp.2350080510

Schraw, G. (1998). Processing and recall differences among seductive details. Journal of Educational Psychology, 90(1), 3-12. https://doi.org/10.1037/0022-0663.90.1.3

Schraw, G., \& Lehman, S. (2001). Situational interest: A review of the literature and directions for future research. Educational Psychology Review, 13(1), 23-52. https://doi.org/10.1023/A:1009004801455 
Serio, Á. D., Ibáñez, M. B., \& Kloos, C. D. (2013). Impact of an augmented reality system on students' motivation for a visual art course. Computers \& Education, 68, 586-596. https://doi.org/10.1016/j.compedu.2012.03.002

Tsai, C. C., \& Hwang, G. J. (2013). Issues and challenges of educational technology research in Asia. The Asia-Pacific Education Researcher, 22(2), 215-216. https://doi.org/10.1007/s40299-012-0038-9

Wei, X., Weng, D., Liu, Y., \& Wang, Y. (2015). Teaching based on augmented reality for a technical creative design course. Computers \& Education, 81, 221-234. https://doi.org/10.1016/j.compedu.2014.10.017

Wu, H. K., Lee, S. W. Y., Chang, H. Y., \& Liang, J. C. (2013). Current status, opportunities and challenges of augmented reality in education. Computers \& Education, 62, 41-49. https://doi.org/10.1016/j.compedu.2012.10.024

Yilmaz, R. M. (2016). Educational magic toys developed with augmented reality technology for early childhood education. Computers in Human Behavior, 54(1), 40-248. https://doi.org/10.1016/j.chb.2015.07.040

$\mathrm{Yu}$, S. J. Jerry Sun, C. Y., \& Oscal Chen, T. C. (2019). Effect of AR-based online wearable guides on university students' situational interest and learning performance. Universal Access in the Information Society, 18(2), 287-299. https://doi.org/10.1007/s10209-017-0591-3

Corresponding author: K.-Y. Chin, kychin.scholar@gmail.com

Copyright: Articles published in the Australasian Journal of Educational Technology (AJET) are available under Creative Commons Attribution Non-Commercial No Derivatives Licence (CC BY-NC-ND 4.0). Authors retain copyright in their work and grant AJET right of first publication under CC BY-NC-ND 4.0.

Please cite as: Chin, K.-Y., \& Wang, C.-S. (2021). Effects of augmented reality technology in a mobile touring system on university students' learning performance and interest. Australasian Journal of Educational Technology, 37(1), 27-42. https://doi.org/10.14742/ajet.5841 